\title{
Evaluation of methods of surfactant administration in the delivery suite?
}

\author{
Hemant Ambulkar, Theodore Dassios, Anne Greenough
}

King's College London, United Kingdom

Submitted: 7 February 2020; Accepted: 20 May 2020

Online publication: 8 January 2021

Arch Med Sci 2023; 19 (1): 116-121

DOI: http://doi.org/10.5114/aoms/122644

Copyright @ 2021 Termedia \& Banach

\begin{abstract}
Surfactant administered in the delivery suite might prevent or reduce the severity of subsequent respiratory distress syndrome. This review describes the evidence for surfactant delivery methods with relationship to their relevance in the delivery suite. The techniques include delivery using a thin catheter with the first breath, by the intubation-surfactant extubation procedure, less invasive surfactant administration (LISA) technique, using a laryngeal mask airway (LMA), or by nebulisation. There have been few randomised trials that have evaluated outcomes using these techniques in the delivery suite, and these were early trials. Currently, practitioners favour use of nasal continuous positive airway pressure with early rescue surfactant. Whether prophylactic surfactant given by the LISA technique or other techniques, such as via a LMA in the delivery suite, is more beneficial merits testing. This will require appropriately designed randomised trials with long-term outcomes.
\end{abstract}

Key words: nebulisation, intubation, laryngeal mask, less invasive surfactant administration.

\section{Introduction}

Delivery of exogenous surfactant to preterm infants for the treatment of respiratory distress syndrome (RDS) was first described in 1980 [1]. A Cochrane review from 2001 included eight randomised controlled trials (RCTs) and compared the effects of prophylactic surfactant administration to surfactant treatment of infants with established RDS. In a secondary analysis of the results of infants born at less than 30 weeks of gestational age, prophylactic surfactant resulted in a decreased risk of pneumothorax, pulmonary interstitial emphysema (PIE), and mortality, with no significant untoward effects [2]. In contrast, a subsequent Cochrane review that included large trials, greater utilisation of maternal corticosteroids, and routine stabilisation of infants on nasal continuous positive airway pressure (nCPAP) did not demonstrate greater benefits of prophylactic surfactant [3]. The increased use of non-invasive respiratory support techniques has meant that fewer infants are receiving prophylactic surfactant. There are now, however, new modes of administration of surfactant available, particularly those that are less invasive or non-invasive. Such techniques could be applicable in the delivery suite. The aim of this review is to assess the efficacy of methods of surfactant administration in the delivery suite set in the context of what we

\author{
Corresponding author: \\ Anne Greenough \\ King's College London, \\ United Kingdom \\ E-mail: \\ anne.greenough@kcl.ac.uk
}


have learned regarding the efficacy of surfactant administration techniques in other delivery suite settings.

\section{Nasopharyngeal administration}

One of the earliest randomised trials assessing surfactant administration investigated the use of artificial lung expanding compound (ALEC) in the delivery suite delivered as close as possible to the first breath. Artificial lung expanding compound was delivered as a liquid to the pharynx of preterm infants born between 25 and 29 weeks of gestational age. The controls received normal saline. Three more doses could be given if the infant remained intubated in the first $24 \mathrm{~h}$. The researchers hypothesised that the surfactant so administered would be spread as lung fluid was absorbed from the airway. The trial demonstrated that surfactant administered in such a way was associated with a reduction in RDS severity, mortality, and intracerebral haemorrhage [4]. In another study in the delivery suite [5], the nasopharynxes of 23 infants born between 27 and 30 weeks of gestational age were suctioned as their head appeared on the perineum or at operative caesarean section incision. Surfactant was instilled into the posterior pharynx before the first breath, and then CPAP was administered for $48 \mathrm{~h}$. Thirteen of 15 infants delivered vaginally weaned quickly to room air and required no further dose of surfactant or endotracheal intubation. Five of the eight infants delivered by caesarean section required subsequent endotracheal intubation soon after birth, and two received further surfactant via the endotracheal tube. A Cochrane review, however, did not find any RCTs or quasi RCTs that evaluated the effect of this method of surfactant administration. The authors of the Cochrane review, however, commented that evidence from animal and observational human studies suggested that this method was potentially safe, feasible, and may be effective, and that well designed trials were needed [6].

\section{Insure}

Surfactant given by transient intubation was first described in 1990 [7]. The IN-SUR-E technique is Intubation followed by SURfactant administration and extubation as early as possible. A Cochrane review reported the findings of six RCTs that compared INSURE to late selective surfactant. The former technique was associated with a lower incidence of mechanical ventilation, air leak syndrome, and BPD. A larger proportion of infants in the early surfactant group received surfactant and received more doses of surfactant [8]. The failure rate of the INSURE method of surfactant admini- stration has been variably reported from $19 \%$ to $69 \%$. A systematic review demonstrated that in 15 studies, the predictors for INSURE failure were lower gestational age and greater RDS severity [9].

In a study of 208 infants born between 25 and 28 weeks of gestational age, there was no significant difference in the primary outcome (mechanical ventilation in the first 5 days) between those given prophylactic surfactant and then extubation to CPAP as soon as possible and selective surfactant according to CPAP failure [10]. In the multicentre, Surfactant, Positive Pressure, and Pulse Oximetry Randomised (SUPPORT) Trial of 1316 infants born between 24 and 27 weeks of gestation, nasal CPAP was compared to intubation and surfactant treatment initiated in the delivery room. The rates of death or BPD did not differ significantly between the two groups, but infants treated with nCPAP required less intubation or postnatal corticosteroids for BPD $(p<0.001)$, required fewer days of mechanical ventilation $(p=0.03)$, and were more likely to be alive and free from the need for mechanical ventilation at 7 days after birth $(p=0.01)[11]$.

\section{Intra-tracheal administration of budesonide-surfactant}

A systematic review of two trials of intra-tracheal administration of budesonide-surfactant demonstrated a $43 \%$ reduced risk of BPD and a $40 \%$ reduced risk of the composite outcome of death/BPD in very low birth weight infants [12]. None of the infants appeared to have received the treatment in the delivery suite. Whether these results can be replicated in a large multi-centre trial needs investigating.

\section{Laryngeal mask airway}

There are a number of adverse effects associated with tracheal intubation of surfactant such as hypoxia and bradycardia and delivery when the tracheal tube is malpositioned. Those risks can be minimised with the use of a laryngeal mask airway (LMA) [13]. In a randomised, multicentre trial, 103 infants between 28 and 35 weeks of gestation $\leq 36 \mathrm{~h}$ old on CPAP were randomised to receive surfactant through an LMA, then placed back on CPAP with no surfactant administered. Surfactant administration through an LMA significantly decreased the rate of intubation and mechanical ventilation ( $38 \%$ vs. $64 \%)(p=0.006)$. There were no serious adverse effects associated with the placement of the LMA or surfactant administration [13]. Although LMAs are typically used for infants with a weight greater than $2 \mathrm{~kg}$ [14], a feasibility study found that LMA could be used to deliver surfactant to premature babies born un- 
der 35 weeks of gestational age with birth weight above $800 \mathrm{~g}$ [15].

A laryngeal mask airway has the advantage of ease of technique of insertion without the need for a laryngoscope and rapidity of the procedure with minimal side effects [16]. In a multicentre $R C T$, videotape of LMA placement was reviewed to determine total procedures, and the time and number of attempts to place the device. The average time to place the device in 36 infants was $88 \mathrm{~s}$, and successful placement was achieved on the first attempt in $69 \%$ of cases. As compared to baseline, heart rate and oxygen saturation increased on average of $1 \mathrm{pbm}$ and decreased on average by $6 \%$, respectively [16]. Thus, use of LMA may be useful in resource-limited settings or for use during transport with personnel with limited expertise in airway management [17-19]. Surfactant administration through LMA fitted with a Y-piece has the advantage over catheter methods of surfactant administration that PEEP can be maintained during delivery of the surfactant, which will keep the alveoli recruited. There can, however, be leakage of surfactant around the LMA cuff; in one study $18 \%$ of infants had more than $50 \%$ of the dose administered recovered from the gastric aspirate [20]. Nevertheless, the authors concluded that surfactant must have reached the lungs in the majority of cases because there was improvement in the fraction of inspired oxygen - more than half of the neonates in the study were weaned to air within $30 \mathrm{~min}$ of receiving the surfactant [13].

There have been case reports of administration of surfactant through the LMA and an RCT in infants, with moderately preterm infants receiving nCPAP with fraction of inspired oxygen $\left(\mathrm{FiO}_{2}\right)$ of 0.30 to 0.60 , which demonstrated that delivery of surfactant via an LMA decreased the need for mechanical ventilation as compared to surfactant administration by endotracheal intubation [21]. The Cochrane review concluded that surfactant administration by LMA resulted in a reduction in the mean $\mathrm{FiO}_{2}$ required to maintain the oxygen saturation between $88 \%$ and $92 \%$ for $12 \mathrm{~h}$ after the intervention. No significant difference, however, was reported in the need for subsequent mechanical ventilation and endotracheal surfactant administration, pneumothorax, days on intermittent positive pressure ventilation, or supplementary oxygen [22]. To date, however, there have been no studies determining whether this is an efficacious method of delivering surfactant in the delivery suite.

\section{Less invasive surfactant administration}

Administration of surfactant via a thin catheter placed in the trachea was first described in 1992 [23].
Less invasive surfactant administration (LISA) is widely practiced in neonatal units in Europe [24]. The gestational age criteria for using LISA is variable, ranging from 23 to 34 weeks of gestation [25-29]. There are variations in the technique including using a feeding tube being guided with or without Magill's forceps [26, 28, 30], a rigid vascular catheter [25, 27, 29], or a specially made catheter (Chiesi Farmaceutici S.p.A). The dose of surfactant to be used for LISA varies from $100 \mathrm{mg} / \mathrm{kg}$ to $200 \mathrm{mg} / \mathrm{kg}$. When the higher dose of surfactant is used, it results in more pronounced and persistent improvement in oxygenation [31] and less need for re-dosing [32, 33]. European consensus guidelines on the management of RDS have recommended the dose of $200 \mathrm{mg} / \mathrm{kg}$ surfactant [32]. Nasal intermittent positive pressure ventilation (NIPPV) can also be used as support during LISA. A randomised controlled trial compared the use of nCPAP to NIPPV as the initial respiratory support, and using LISA if the infant required an $\mathrm{FiO}_{2}$ of more than 0.4 to maintain the target oxygen saturation level between 90 and 95\%. There was also reduced need for surfactant in the NIPPV compared to the nCPAP group ( $O R=0.32, p=0.002)$, but no significant difference in the incidence of moderate to severe BPD between the two groups [34].

Adverse effects of LISA include coughing, vomiting, surfactant reflux, bradycardia, apnoea, and desaturation. Bradycardia and desaturation may cease, however, if the procedure is temporarily suspended, and a longer duration of administration may prevent those adverse effects. Non-pharmacological interventions such as wrapping/ swaddling the infant have been used with the LISA technique to keep the infant calm. Others have used oral sucrose or medications such as atropine, ketamine, propofol, morphine, and fentanyl [35-38]. Morphine has the disadvantage of having a long half-life, and propofol use can be associated with significant hypotension [39]. Remifentanil is a synthetic opioid with a short duration of action; using that agent in a pilot study of 21 infants with a gestational age of 29 to 32 weeks, none of the infants had significant bradycardia, hypotension, or chest wall rigidity [40]. In a Nordic survey, approximately half the clinicians preferred giving pre-medications before the procedure [41]. In a UK nationwide survey, $49 \%$ of units used no medication with LISA and most commonly opioids were used $31 \%$ of respondents) [35]. In an RCT, 78 infants were randomised to receive either low dose sedation (1 $\mathrm{mg} / \mathrm{kg}$ propofol intravenous) or no premedication. Low-dose sedation was associated with an increased comfort score, but the need for transient non-invasive ventilation was increased [42]. A catheter inserted too deep can result in unilateral surfactant deposition leading to pneumotho- 
rax and PIE secondary to unilateral lung hyperinflation, but this has not been seen as a major problem in studies to date [43]. There are other possible adverse effects of LISA. In an animal model, the surfactant distribution was lower following LISA compared to surfactant delivered via an endotracheal tube; nevertheless, the "LISA" lambs had better oxygenation [44]. In an in vitro study, CPAP transmission was significantly and variably reduced during LISA [45]. A retrospective observational study showed that the failure rates of LISA were around $30 \%$. This may relate to the poorer respiratory drive in more immature infants [46].

A meta-analysis showed a reduction in the composite outcome of death or BPD at 36 weeks $(\mathrm{RR}=0.75, p=0.01)$, occurrence of $\mathrm{BPD}$ at 36 weeks ( $R R=0.72, p=0.03)$, and the need for ventilation when compared to the standard method of surfactant delivery [47]. Whether LISA used in the delivery suite is of benefit or harm has not been tested in RCTs.

In a large observational, cohort study from the German Neonatal Network including 7533 VLBW infants, LISA was associated with improved outcomes, but in infants less than 26 weeks of gestational age there was an increase in focal intestinal perforations [48]. Future RCTs should integrate safety analyses in this particular sub-group.

\section{Nebulisation}

Instillation of a surfactant "bolus" into the trachea can cause transient airway obstruction, which may lead to hypoxia and hypotension. This complication is avoided by nebulisation or aerosolisation of the surfactant, which can result in a more homogenous distribution in the lungs. There can, however, be a lag period in the response to surfactant when administered via nebuliser [49]. The particle size of aerosol droplets should be between 1 to $5 \mu \mathrm{m}$ to be best delivered to the lungs [50]. The aerosol particles should be small enough to bypass the nasopharynx, but also large enough not to be exhaled. Vibrating mesh nebulisers have been found to be most effective in delivering medications to the lungs [51]. The disadvantage of nebulisation is that it leads to loss of surfactant in the upper airways and oesophagus, with less than $10 \%$ delivered to the lower airways [52]. Even with this lower deposition in the lungs, nebulised surfactant improved ventilation and lung mechanics in animal models [53]. Surfactant by aerosolisation has been shown to be delivered effectively to infants on non-invasive respiratory support such as high-flow nasal cannula, CPAP, and synchronised inspiratory positive airway pressure [54]. Animal studies have shown that it is possible to deliver aerosols with highfrequency oscillatory ventilation (HFOV) [55].
In a randomised trial nebulised surfactant in combination with nasal CPAP was compared to nasal CPAP alone in 360 neonates of $29-31+6$ or $32-33+6$ weeks gestational age with mild to moderate respiratory distress (a fraction of inspired oxygen of $0.22-0.30$ ). The infants were all less than $4 \mathrm{~h}$ of age, had clinical signs suggestive of evolving mild to moderate RDS, and required nCPAP of 5 to $8 \mathrm{cmH}_{2} \mathrm{O}$ and supplemental fractional inspired oxygen $\left(\mathrm{FiO}_{2}\right)$ of 0.22 to 0.30 to maintain an oxygen saturation between $86 \%$ and $94 \%$. Surfactant was given at a dose of $200 \mathrm{mg} / \mathrm{kg}$ by a vibrating membrane nebuliser soon after randomisation and repeated $12 \mathrm{~h}$ after for persistent respiratory distress or oxygen requirement. There was a reduction in mechanical ventilation in the 32-33 + 6 weeks of gestation infants who received surfactant nebulisation with CPAP [45]. In another study, there was a significant reduction in the clinical manifestations of severe RDS as demonstrated by the Silverman score, alveolar-arterial oxygen $\left[(\mathrm{A}-\mathrm{a}) \mathrm{O}_{2}\right.$ ] gradient, and the $\mathrm{PaCO}_{2}$ levels when comparing aerosolised surfactant with CPAP to CPAP alone [56].

\section{Comparison of techniques}

A systematic review compared seven different respiratory strategies in 5598 infants born before 33 weeks of gestational age: nCPAP alone, LISA, INSURE, nebulised surfactant while receiving CPAP, NIPPV, surfactant given by LMA followed by CPAP and mechanical ventilation [57]. The report used network meta-analyses or multiple treatment comparison meta-analyses to provide a framework for analysing and interpretating more than two interventions to understand the evidence of network of multiple interventions as a whole. Compared with mechanical ventilation, it was reported that LISA had lower odds of primary outcome (death or BPD at 36 weeks PMA, odds ratio $(O R=0.49)$, BPD $(O R=0.53)$, and severe intraventricular haemorrhage $(O R=0.44)$ ). Compared with nasal CPAP alone, it was reported that LISA had lower odds of primary outcome $(O R=0.58)$ and air leak $(O R=0.24)$. Ranking probabilities indicated that LISA was the best strategy with a surface under the cumulative ranking curve of 0.85 to 0.94 . However, when limited to high-quality evidence, some significant findings for LISA compared to other strategies became non-significant and the lower likelihood of death associated with LISA was not robust. Furthermore, there was no direct RCT comparing LISA to LMA, LMA to aerosolisation, or LISA to aerosolisation. Furthermore, the studies performed and analysed used different surfactants, although both LMA and LISA and some of INSURE trials mostly used Curosurf, while aerosolised surfactant studies have used several 
surfactants. Thus, no definitive conclusions can be drawn. Direct comparisons are required.

\section{Conclusions}

Other than the widely used administration via the endotracheal tube, a number of other methods have emerged in recent years as alternatives for surfactant administration in prematurely born infants. Administration of surfactant via a laryngeal mask is safe and efficient but has not been adequately tested in very prematurely born infants. Less invasive surfactant administration is also feasible and efficient, but a number of questions remain unanswered regarding the choice of sedation, equipment, administration in the delivery unit or the neonatal unit, and dosing regimens. It has also not been proven whether the most immature infants who have poor respiratory drive are suitable candidates for less invasive administration. The efficacy of other methods such as surfactant nebulisation or the combined intratracheal administration of budesonide and surfactant will require more conclusive studies before their routine application in clinical care is recommended.

\section{Conflict of interest}

The authors declare no conflict of interest.

\section{References}

1. Fujiwara T, Maeta H, Chida S, Morita T, Watabe Y, Abe T. Artifical surfactant therapy in hyaline membrane disease. Lancet 1980; 1: 55-9.

2. Soll R. Prophylactic synthetic surfactant for preventing morbidity and mortality in preterm infants. Cochrane Database Syst Rev 2003; 1: CD001079.

3. Rojas-Reyes MX, Morley CJ, Soll R. Prophylactic versus selective use of surfactant in preventing morbidity and mortality in preterm infants. Cochrane Database Syst Rev 2012; 3: CD000510.

4. Morley CJ, Greenough A, Miller NG, et al. Randomized trial of artificial surfactant (ALEC) given at birth to babies from 23 to 34 weeks gestation. Early Hum Dev 1988; 17: 41-54.

5. Kattwinkel J, Robinson M, Bloom BT, Delmore P, Ferguson JE. Technique for intrapartum administration of surfactant without requirement for an endotracheal tube. J Perinat 2004; 24: 360-5.

6. Abdel-Latif ME, Osborn DA. Pharyngeal instillation of surfactant before the first breath for prevention of morbidity and mortality in preterm infants at risk of respiratory distress syndrome. Cochrane Database Syst Rev 2011; 3: CD008311.

7. Victorin LH, Deverajan LV, Curstedt T, Robertson B. Surfactant replacement in spontaneously breathing babies with hyaline membrane disease - a pilot study. Biol Neonate 1990; 58: 121-6.

8. Stevens TP, Blennow M, Myers EH, Soll R. Early surfactant adminsitration with brief ventilation vs selective surfactant and continued mechanical ventilation for preterm infants with or at risk for respiratory distress syndrome. Cochrane Database Syst Rev 2007; 4: CD003063.
9. De Bisschop B, Peeters L, Sonnaert M. Early predictors for Intubation-SURfactant-SURfactant-Extubation failure in preterm infants with neonatal respiratory distress syndrome: a systematic review. Neonatology 2019; 22: 1-13.

10. Sandri F, Plavka R, Ancora G, et al. Prophylactic or early selective surfactant combined with nCPAP in very preterm infants. Pediatrics 2010; 125: e1402-9.

11. Finer N, Carlo W, Walsh M, et al.; Support Study Group of the Eunice Kennedy Shriver NICHD Neonatal Research Network. Early CPAP versus surfactant in extremely preterm infants. N Engl J Med 2010; 362: 1970-9.

12. Venkataraman R, Kamaluddeen M, Hasan SU, Robertson HL, Lodha A. Intratracheal administration of budesonide-surfactant in prevention of bronchopulmonary dysplasia in very low birth weight infants: a systematic review and meta-analysis. Pediatr Pulmonol 2017; 52: 968-75.

13. Roberts KC, Brown R, Lampland AL, et al. Laryngeal mask airway for surfactant administration in neonates: a randomized, controlled trial. J Pediatr 2018; 193: 40-6.

14. Wyllie J, Bruinenberg J, Roehr CC, Rüdiger M, Trevisanuto D, Urlesberger B. European Resuscitation Council Guidelines for Resuscitation 2015. Section 7. Resuscitation and support of transition of babies at birth. Resuscitation 2015; 95: 249-63.

15. Trevisanuto D, Grazzina N, Ferrarese P, Micaglio M, Verghese C, Zanardo V. Laryngeal mask airway used as a delivery conduit for the administration of surfactant to preterm infants with respiratory distress syndrome. Biol Neonate 2005; 87: 217-20.

16. Wanous AA, Wey A, Rudser KD, Roberts KD. Feasibility of laryngeal mask airway device placement in neonates. Neonatology 2017; 111: 222-7.

17. Trevisanuto D. Laryngeal mask airway for the interhospital transport of neonates. Pediatrics 2005; 115: e109-11.

18. Trevisanuto D. The laryngeal mask airway: potential applications in neonates. Arch Dis Child Fetal Neonatal Ed 2004; 89: F485-9.

19. Nematova RI, Guthrie SO. The introduction of the laryngeal mask airway for surfactant administration in neonates with respiratory distress in Azerbaijan. Eur J Clin Sci 2019; 2: 63-7.

20. Roberts KD, Brown R, Lampland AL, et al. Laryngeal mask airway for surfactant administration in neonates: a randomized, controlled trial. J Pediatr 2018; 193: 40-46.e1.

21. Pinheiro JM, Santana-Rivas Q, Pezzano C. Randomized trial of laryngeal mask airway versus endotracheal intubation for surfactant delivery. J Perinatol 2016; 36: 196-201.

22. Dani C, Corsini I, Poggi C. Risk factors for Intubation-Surfactant-Extubation (INSURE) Failure and Multiple INSURE Strategy in preterm infants. Early Hum Dev 2012; 88 Suppl 1: S3-4.

23. Verder H, Agertoft L, Albertsen P, et al. Surfactant treatment of newborn infants with respiratory distress syndrome primarily treated with nasal continuous positive air pressure. A pilot study. Ugeskr Laeger 1992; 154: 2136-9.

24. Kurepa D, Perveen S, Lipener Y, Kakkilaya V. The use of less invasive surfactant administration (LISA) in the United States with review of the literature. J Perinatol 2019; 39: 426-32.

25. Göpel W, Kribs A, Ziegler A, et al. Avoidance of mechanical ventilation by surfactant treatment of spontaneously breathing preterm infants (AMV): an open-label, randomised, controlled trial. Lancet 2011; 378: 1627-34.

26. Heidarzadeh M, Mirnia K, Bagher Hoseini M, et al. Surfactant administration via thin catheter during sponta- 
neous breathing: randomized controlled trial in Alzahra Hospital. Iranian J Neonatol 2013; 4: 5-9.

27. Bao Y, Zhang G, Wu M, Ma L, Zhu J. A pilot study of less in vasive surfactant administration in very preterm infants in a Chinese Tertiary Center. BMC Pediatr 2015; 15: 21.

28. Mohammadizadeh M, Sadeghnia A, Ardestani A. Early administration of surfactant via a thin intratracheal catheter in preterm infants with respiratory distress syndrome: feasibility and outcome. J Res Pharm Pract 2015; 4: 31-6.

29. Kribs A, Roll C, Göpel W, et al. Nonintubated surfac tant application vs conventional therapy in extremely preterm infants: a randomized clinical trial. JAMA Pediatr 2015; 169: 723-30.

30. Kribs A, Hummler $\mathrm{H}$. Ancillary therapies to enhance success of non-invasive modes of respiratory support approaches to delivery room use of surfactant and caffeine? Sem Fetal Neonatal Med 2016; 21: 212-8.

31. Dargaville P, Aiyappan A, De Paoli AG, et al. Minimally-invasive surfactant therapy in preterm infants on continuous positive airway pressure. Arch Dis Child Fetal Neo natal Ed 2013; 98: 122-6.

32. Sweet DG, Carnielli V, Greisen G, et al. European consensus guidelines on the management of respiratory distress syndrome - 2019 update. Neonatology 2019; 115: 432-50.

33. Singh N, Halliday HL, Stevens TP, Suresh G, Soll R, RojasReyes MX. Comparison of animal-derived surfactants for the prevention and treatment of respiratory distress syndrome in preterm infants. Cochrane Database Syst Rev 2015; 12: CD010249.

34. Oncel MY, Arayici S, Uras N, et al. Nasal continuous positive airway pressure versus nasal intermittent positive-pressure ventilation within the minimally invasive surfactant therapy approach in preterm infants: a ran domised controlled trial. Arch Dis Child Fetal Neonatal Ed 2016; 101: F323-8.

35. Jeffreys E, Hunt K, Dassios T, Greenough A. UK survey of less invasive surfactant administration. Arch Dis Child Fetal Neonatal Ed 2019; 104: F567.

36. Klotz D, Porcaro U, Fleck T, Fuchs H. European perspective on less invasive surfactant administration - a survey. Eur J Pediatr 2017; 176: 147-54.

37. Descamps CS, Sophie C, Chevallier M, et al. Propofol for sedation during less invasive surfactant administration in preterm infants. Arch Dis Childhood Fetal Neonatal Ed 2017; 102: F465.

38. Shim GH. Update of minimally invasive surfactant therapy. Korean J Pediatr 2017; 60: 273-81.

39. Welzing L, Kribs A, Eifinger F, Huenseler C, Oberthuer A, Roth B. Propofol as an induction agent for endotracheal intubation can cause significant arterial hypotension in preterm neonates. Paediatr Anaesth 2010; 20: 605-11.

40. Audil L, Kribs A, Huenseler C, Eifinger F, Mehler K, Roth B. Remifentanil for INSURE in preterm infants: a pilot study for evaluation of efficacy and safety aspects. Acta Paediatr 2009; 98: 1416-20.

41. Heiring C, Jonsson B, Andersson S, Björklund LJ. Survey shows large differences between the nordic countries in the use of less invasive surfactant administration. Acta Paediatr 2017; 106: 382-6.

42. Dekker J, Lopriore E, van Zanten HA, Tan RNGB, Hooper SB, Te Pas AB. Sedation during minimal invasive surfactant therapy: a randomised controlled trial. Arch Dis Child Fetal Neonatal Ed 2019; 104: F378-83.

43. Wu W, Shi Y, Li F, Wen Z, Liu H. Surfactant administration via a thin endotracheal catheter during spontaneous breathing in preterm infants. Pediatr Pulmonol 2017; 52: 844-54.

44. Berggren E, Liljedahl M, Winbladh B, et al. Pilot study of nebulized surfactant therapy for neonatal respiratory distress syndrome. Acta Paediatr 2000; 89: 460-5.

45. Minocchieri S, Berry CA, Pillow J. Nebulised surfactant to reduce severity of respiratory distress: a blinded, parallel, randomised controlled trial. Arch Dis Child Fetal Neonatal Ed 2019; 104: F313-9.

46. Janssen LC, Van Der Spil J,van Kaam AH, et al. Minimally invasive surfactant therapy failure: risk factors and outcome. Arch Dis Child Fetal Neonatal Ed 2019; 104: F636-42.

47. Aldana-Aguirre JC, Pinto M, Featherstone RM, Kumar M. Less invasive surfactant administration versus intubation for surfactant delivery in preterm infants with respiratory distress syndrome: a systematic review and meta-analysis. Arch Dis Child Fetal Neonatal Ed 2017; 102: F17-23.

48. Hartel C, Paul P, Hanke K, et al. Less invasive surfactant administration and complications of preterm birth. Sci Rep 2018; 8: 8333.

49. Willson DF. Aerosolized surfactants, anti-inflammatory drugs, and analgesics. Respir Care 2015; 60: 774-93.

50. Barkhuff WD, Soll RF. Novel surfactant administration techniques: will they change outcome? Neonatology 2019; 115: 411-22.

51. Ehrmann S. Vibrating mesh nebulisers - can greater drug delivery to the airways and lungs improve respiratory outcomes? Eur Respir Pulmonol Dis 2018; 4: 33-43.

52. Pillow J, Minocchieri S. Innovation in surfactant therapy II: surfactant administration by aerosolization. Neonatology 2012; 101: 337-44.

53. Lewis JF, Ikegami M, Jobe AH, Absolom D. Physiologic responses and distribution of aerosolized surfactant (Survanta $^{\oplus}$ ) in a nonuniform pattern of lung injury. Am Rev Respir Dis 1993; 147: 1364-70.

54. Sunbul FS, Fink JB, Harwood R, Sheard M, Zimmerman RD, Ari A. Comparison of HFNC, bubble CPAP and SIPAP on aerosol delivery in neonates: an in-vitro study. Pediatr Pulmonol 2015; 50: 1099-106.

55. Sood BG, Shen Y, Latif Z, Galli B, Dawe EJ, Haacke ME. Effective aerosol delivery during high-frequency ventilation in neonatal pigs. Respirology 2010; 15: 551-5.

56. Jorch G, Hartl H, Roth B, et al. Surfactant aerosol treatment of respiratory distress syndrome in spontaneously breathing premature infants. Pediatr Pulmonol 1997; 24: 222-4.

57. Isayama T, Iwami H, McDonald S, Beyene J. Association of noninvasive ventilation strategies with mortality and bronchopulmonary dysplasia among preterm infants: a systematic review and meta-analysis. JAMA 2016; 316: 611-24. 